\title{
Paper supports in electrocatalysis: Weak contact catalysis with seed- mediated grown gold nanoparticle deposits
}

\author{
$\operatorname{AUTHOR}(S)$ : \\ Oyama, Munetaka; Nakashima, Daisuke; \\ Cummings, Charles Y.; Marken, Frank
}

\section{CITATION:}

Oyama, Munetaka ...[et al]. Paper supports in electrocatalysis: Weak contact catalysis with seed-mediated grown gold nanoparticle deposits. Electrochemistry Communications 2011, 13(1): 68-71

\section{ISSUE DATE:}

2011-01

URL:

http://hdl.handle.net/2433/134596

\section{RIGHT:}

(C) 2010 Elsevier B.V.; This is not the published version. Please cite only the published version.; この論文は出版社版でありません。引用の際に は出版社版をご確認ご利用ください。 


\title{
Paper Supports in Electrocatalysis: Weak Contact Catalysis with Seed-Mediated Grown Gold Nanoparticle Deposits
}

\author{
Munetaka Oyama, ${ }^{1}{ }^{*}$ Daisuke Nakashima ${ }^{1}$, Charles Y. Cummings ${ }^{2}$, \\ and Frank Marken ${ }^{2, *}$
}

(1) Department of Material Chemistry, Graduate School of Engineering, Kyoto University, Nishikyo-ku, Kyoto 615-8520, Japan

(2) Department of Chemistry, University of Bath, Bath BA2 7AY, UK

* Corresponding Author: Munetaka Oyama

Tel: $\quad+81-75-383-3074, \quad$ Fax: $\quad+81-75-383-3074$

E-mail: m.oyama@kx8.ecs.kyoto-u.ac.jp 


\section{Abstract}

Paper surfaces (Whatman filter papers, Kimwipes®, and Japanese Washi papers) were employed as support for gold nanoparticles (AuNPs) deposited by the seed-mediated growth method. The AuNP-modified paper or textile was brought into "weak" (or non-permanent) contact with a glassy carbon electrode and immersed into aqueous electrolyte media. Electrochemical responses for the $\mathrm{Fe}(\mathrm{CN})_{6}{ }^{4-} / \mathrm{Fe}(\mathrm{CN})_{6}{ }^{3-}$ redox system in $0.1 \mathrm{M}$ phosphate buffer $(\mathrm{pH} 7.0)$ and $1.0 \mathrm{M} \mathrm{KCl}$ solutions were investigated by voltammetry and impedance methods. Even for weakly contacted AuNP catalysts of relatively low density faster electron transfer was observed. Particle sizes of at least 20 $\mathrm{nm}$ diameter were required. There was no permanent contact from AuNP catalysts to the electrode and the process was therefore termed "weak contact catalysis". The method is proposed as a rapid and novel catalyst screening tool with potential applications in fuel cell and sensor technologies.

Key words: Modified electrodes; gold nanoparticles; electron-transfer reactions; textile; paper; catalyst support; seed-mediated growth method; voltammetry; impedance; contact-electrocatalysis. 


\section{Introduction}

Metal nanoparticle catalysts are commonly employed and immobilized directly at the surface of carbon or ceramic electrodes. Here gold nanoparticles (AuNPs) are employed but in contrast to the conventional immobilization method, the catalyst is immobilized onto a paper or textile substrate. In processes with conventionally immobilized nanoparticle catalysts "strong contact" or adhesion between substrate and nanoparticle is important (see Figure 1A). Here, it is demonstrated that "weak contact" catalysis is feasible where the catalysts is immobilized on a separate substrate (e.g. paper or a textile) and the electrode is simply placed on this substrate and then removed again (see Figure 1B).

In recent years, there have been many reports on the application of electrodes modified with AuNPs e.g. for electroanalysis [1,2,3]. The use of a three-dimensional (3D) sol-gel silica networks to hold AuNPs has been reported [4,5,6,7,8,9,10,11,12]. Raj and coworkers reported various successful electroanalytical applications with this approach [6-10]. AuNPs are employed here as a model catalyst where a seed mediated-growth procedure allows particle properties to be controlled. The use of paper-like materials or cellulose substrates in modified electrodes has been reported previously $[13,14,15]$.

Inspired by the above studies, but seeking versatile supports, we started some trials to modify paper materials with AuNPs. Perceived advantages are: (i) redox species may be transported through the paper substrate for electron-transfer reactions to/from the electrode, (ii) a new type of "weak contact" modification may be possible with AuNPs bound strongly to the paper support but not to the electrode, and (iii) the electrode is 
catalytic only during intermittent contact to catalyst particles which in future could be exploited for catalyst screening.

[Fig. 1]

\section{Experimental}

\subsection{Reagents, Materials, and Instrumentation}

Cetyltrimethyammonium bromide $(\mathrm{CTAB})$ and $\mathrm{HAuCl}_{4} \cdot 3 \mathrm{H}_{2} \mathrm{O}$ were purchased from Aldrich. All aqueous solutions were prepared with ultra-pure water (Millipore WR600A, Yamato Co., Japan). Scanning electron microscopy (SEM) images were obtained with a field emission SEM instrument (JSM-7400F, JEOL) or a conventional SEM (JSM6480LV, JEOL). Electrochemical experiments were carried out with an EG\&G M263A potentiostat/galvanostat (Princeton Applied Research, USA) and a 5210 lock-in amplifier (Princeton Applied Research, USA) controlled by M270 and M398. In electrochemical measurements, a platinum wire and an $\mathrm{Ag} \mid \mathrm{AgCl}(3 \mathrm{M} \mathrm{NaCl})$ electrode were employed as the counter and reference electrodes, respectively.

\subsection{Modification of Textile or Paper Materials with AuNPs}

A seed-mediated method for surface modification $[16,17]$ was used to modify some paper materials with AuNPs. First, a substrate is immersed in the seed-solution containing ca. $4 \mathrm{~nm}$ diameter $\mathrm{Au}$ nano-seed particles [18], and then immersed in the growth solution containing ascorbic acid, cetyltrimethylammonium bromide (CTAB) and $\mathrm{HAuCl}_{4}$. Hence, paper materials should be strong enough for immersion in these 
aqueous solutions. As the paper materials, we chose some filter papers (No. 1 and No. 4, Whatman Ltd.), Kimwipes® (S-200, Nippon Paper Cresia Co., Ltd.), and some traditional Japanese papers (washi), because these are relatively strong and absorbent.

Procedure: $2.0 \mathrm{~mL}$ of $0.010 \mathrm{M} \mathrm{HAuCl}_{4}$ and $2.0 \mathrm{~mL}$ of $0.010 \mathrm{M}$ trisodium citrate aqueous solutions were added into $80 \mathrm{~mL}$ of pure water. By taking $10.0 \mathrm{~mL}$ of this solution into a test tube, a seed solution was prepared by adding $0.25 \mathrm{~mL}$ of ice-cooled $0.1 \mathrm{M} \mathrm{NaBH}_{4}$ aqueous solution and stirring for 2 hrs. A piece of paper (ca. $1 \mathrm{~cm} \times 2$ $\mathrm{cm}$ ) was immersed in the seed solution for $2 \mathrm{hrs}$, and then it was washed with pure water and dried in $\mathrm{N}_{2}$ gas. The growth solution was prepared by addition of $1.0 \mathrm{~mL}$ of $0.01 \mathrm{M} \mathrm{HAuCl}_{4}$ and $0.2 \mathrm{~mL}$ of $0.1 \mathrm{M} \mathrm{L}$-ascorbic acid, and $0.2 \mathrm{~mL}$ of $0.1 \mathrm{M} \mathrm{NaOH}$ aqueous solutions into $40.0 \mathrm{~mL}$ of $0.1 \mathrm{M} \mathrm{CTAB}$ aqueous solution. Into a $10 \mathrm{ml}$ aliquot of this growth solution, the piece of paper treated in the seed solution and dried was immersed for $24 \mathrm{hrs}$ at $28{ }^{\circ} \mathrm{C}$, washed with pure water, and dried in $\mathrm{N}_{2}$ gas. For all the paper materials tested, AuNPs could be successfully modified using the seed-mediated growth method [18] as confirmed by a reddish color (see Fig. 1E).

\subsection{Preparation of Paper-Modified Electrodes}

A glassy carbon (GC) electrode (BAS, Japan; 6 mm outer diameter, 3 mm diameter GC disc) was employed with a $6 \mathrm{~mm}$ diameter piece of the AuNP-modified paper placed onto the surface, and fixed tightly with Nylon mesh (see Fig. 1F). The GC electrodes were used as received (unpolished), or, after polishing with a PK-3 kit containing alumina and diamond solutions (BAS, Japan) following the recommended procedures.

\section{Results and Discussion}




\subsection{Modification of Paper Supports with AuNPs}

With the seed-mediated growth method AuNPs can be attached and grown on ITO substrates [18] as well as GC substrates [19]. The successful attachment of AuNPs to paper materials was confirmed by the characteristic coloration. In the case of Kimwipes ${ }^{\circledR}$ (see Fig. 1D) a pink color was observed after the treatment in the seed solution. The color deepened to reddish (see Fig. 1E) after the growth treatment. A similar color change was observed for all the paper materials examined. The reddish color that originates from the localized surface plasmon around $520 \mathrm{~nm}$ provides the evidence that AuNPs were bound in the paper matrix independently, i.e., not connecting to each other.

\section{[Fig. 2]}

The electrical conductance or sheet resistance of the AuNP-modified paper materials could not be measured by conventional methods, i.e., the AuNP-modified papers were insulators based on measurements with a sheet resistance meter. Fig. 2B shows the FE-SEM images of AuNP-modified Kimwipes ${ }^{\circledR}$. Although the focusing and zooming were quite difficult due to charging, we could observe some AuNPs in the magnified image in a quick-view mode. The typical size is roughly $20-30 \mathrm{~nm}$, so we believe that the Au nanoseed particles of ca. $4 \mathrm{~nm}$ in fact grew in the growth solution and remained on the surfaces of Kimwipes ${ }^{\circledR}$ substrates. The size of AuNPs in Fig. $2 B$ is in accordance with the reddish color in Fig.1E. The present FE-SEM results indicate that AuNPs on Kimwipes ${ }^{\circledR}$ do not connect to each other and are distributed sparsely over the paper material. 


\subsection{Electrochemical Measurements with AuNP-Paper-Modified GC Electrodes}

Figure $2 \mathrm{C}$ shows the cyclic voltammograms for the oxidation of $1.0 \mathrm{mM} \mathrm{Fe}(\mathrm{CN})_{6}{ }^{4-}$ (in $0.10 \mathrm{M}$ phosphate buffer solution, $\mathrm{PBS} \mathrm{pH} 7.0$, and in $1.0 \mathrm{M} \mathrm{KCl}$ solution) measured with an unpolished GC electrode. In the absence of AuNPs the redox responses were relatively irreversible both in $\mathrm{PBS}$ and $\mathrm{KCl}$ solution. Cyclic voltammograms were obtained also with a polished GC electrode (see Fig. 2D) with a peak separation of ca. $128 \mathrm{mV}$ in $\mathrm{KCl}$ and $226 \mathrm{mV}$ in PBS (scan rate $50 \mathrm{mVs}^{-1}$ ). Next, we observed the electrochemical responses with the AuNP-paper-modified GC electrodes. Almost fully reversible voltammograms were observed (see Fig. 2E, obtained after 10 minute soaking). The peak-to-peak separation was $67 \mathrm{mV}$ in the $\mathrm{KCl}$ and $64 \mathrm{mV}$ in PBS (scan rate $50 \mathrm{mVs}^{-1}$ ). This result indicates that the AuNPs modified paper support promotes the electron-transfer reaction. Kimwipes ${ }^{\circledR}$ only without AuNPs have an insignificant effect (see Fig. 2G).

[Fig. 3]

By comparing the results in Fig. 2D and Fig. 2E, we could recognize that the effect of AuNP-paper-modification is significant. Data for a voltammetry experiment conducted in PBS without redox system is shown in Fig. 2F where small gold oxidation and reduction processes are clearly visible (indicated by $*$ symbols) with a charge of ca. 2 $\mu \mathrm{C} \mathrm{cm}$. For a bare gold surface a charge of ca. $1200 \mu \mathrm{C} \mathrm{cm}$ is observed [20], and therefore a density of ca. $130 \times 10^{6}$ nanoparticles $\mathrm{cm}^{-2}$ can be estimated (assuming 20 $\mathrm{nm}$ diameter gold nanoparticles in weak contact to the electrode), which implies 
nanoparticles with an approximate distance of ca. $200 \mathrm{~nm}$. This estimate is not inconsistent with the SEM image in Fig. 2B.

The electrochemical impedance data confirmed a significant effect of AuNP-paper modification on the rate of electron transfer (see Fig. 2H). For the AuNP-paper-modified GC electrode a significant decrease in charge transfer resistance is observed in comparison with the polished or unpolished GC electrode in PBS. These results are in accordance with the changes in the cyclic voltammetric responses for the unpolished GC electrode (Fig. 2C), the polished GC electrode (Fig. 2D), and the AuNP-paper-modified unpolished GC electrode (Fig. 2E).

For obtaining the responses in Fig. 2E, we need to pre-soak the electrode for 10 minutes in the case of the Kimwipes ${ }^{\circledR}$ support. When we observed cyclic voltammograms at shorter soaking time, e.g. $0,2.5,5$, and 7.5 minutes, less developed current peaks were observed indicating slow penetration of the test solution into the paper fibers. Kimwipes ${ }^{\circledR}$ showed the quickest stabilization time. In the cases of other papers (filter papers and some Japanese papers), the time required to give stable responses was typically $20-40$ minutes.

After electrochemical measurements the paper substrate was removed form the GC electrode. Cyclic voltammograms after the removal of the AuNP-modified paper showed slightly better reversibility compared with that in Fig. $2 \mathrm{C}$ but considerably worse compared with Fig. 2E. When immersed in PBS no significant oxidation reduction responses for immobilized gold were seen. 


\subsection{Control of the Paper-Attached Amount and Reactivity of AuNP Catalyst}

The amount or diameter of AuNPs attached to the paper supports may influence the electrochemical responses. Without growth treatment no enhancement of the rate of electron transfer is observed. Only after growth to ca. $20 \mathrm{~nm}$ diameter significant effects are observed. This observation is probably linked to (i) the interaction between the electrode surface and the paper material and (ii) the roughness of the interacting surfaces. Nanoparticles strongly adsorbed onto the paper support will require a minimum diameter in order to reach into the double layer region of the electrode surface. Next, agitation during both the seeding and the growth treatment allowed higher particle densities to be achieved (based on the deepening of the colour). However, the electrochemical responses of the $\mathrm{Fe}(\mathrm{CN})_{6}{ }^{4-} / \mathrm{Fe}(\mathrm{CN})_{6}{ }^{3-}$ couple simply remained reversible with a peak with typically $64-67 \mathrm{mV}$ peak-to-peak separation.

\section{Conclusions}

A AuNP-modified paper support is proposed to provide a "weak contact" from AuNPs to the GC electrode surface. The modification of papers with AuNPs was possible using the seed-mediated growth method with Kimwipes® paper giving the most rapid response time. The AuNPs-paper-modified electrode can be proposed as a new type electrode that can promote electron-transfer or other types of catalytic reactions. This electrode could be effective for screening purposes where a library of catalyst materials (different composition, different sizes, etc.) is pre-deposited onto an appropriate paper substrate, pre-soaked in solution, and then simply brought into contact with a 
macroscopic electrode.

\section{Acknowledgements}

This work was supported in part by a Grant-in-Aid for Scientific Research from the Ministry of Education, Culture, Science, Sports and Technology, Japan, No. 20550074.

\section{References}

[1] C. M. Welch, R. G. Compton, Anal. Bioanal. Chem. 384 (2006) 601.

[2] F. W. Campbell, R. G. Compton, Anal. Bioanal. Chem. 396 (2010) 241.

[3] M. Oyama, Anal. Sci. 26 (2010) 1.

[4] S. Bharathi, M. Nogami, S. Ikeda, Langmuir 17 (2001) 1.

[5] L. Wang, E. Wang, Electrochem. Commun. 6 (2004) 49.

[6] C. R. Raj, B. K. Jena, Chem. Commun. (2005) 2005.

[7] B. K. Jena, C. R. Raj, Chem. Eur. J. 12 (2006) 2702.

[8] B. K. Jena, C. R. Raj, Anal. Chem. 78 (2006) 6332.

[9] B. K. Jena, C. R. Raj, J. Phys. Chem. C 111 (2007) 6228.

[10] B. K. Jena, C. R. Raj, Anal. Chem. 80 (2008) 4836.

[11] P. Kalimuthu, S. A. John, J. Electroanal. Chem. 617 (2008) 164.

[12] P. Kannan, S. A. John, Electrochim. Acta. 55 (2010) 3497.

[13] M. J. Bonné, E. V. Milsom, M. Helton, W. Thielemans, S. Wilkins, F. Marken, Electrochem. Commun. 9 (2007) 1985. 
[14] M. J. Bonné, K. J. Edler, J. G. Buchanan, D. Wolverson, E. Psillakis, M. Helton, W. Thielemans, F. Marken, J. Phys. Chem. C 112 (2008) 2660.

[15] M. J. Bonné, E. Galbraith, T. D. James, M. J. Wasbrough, K. J. Edler, A. T. A. Jenkins, M. Helton, A. McKee, W. Thielemans, E. Psillakis, F. Marken, J. Mater. Chem., 20 (2010) 588.

[16] M. Kambayashi, J. Zhang, M. Oyama, Cryst. Growth Des. 5 (2005) 81.

[17] J. Zhang, M. Kambayashi, M. Oyama, Electrochem. Commun. 6 (2004) 6.

[18] N. R. Jana, L. Gerheart, C. J. Murphy, J. Phys. Chem. B 105 (2001) 4065.

[19] M. Oyama, S. Yamaguchi, J. Zhang, Anal. Sci. 25 (2009) 249.

[20] E. V. Milson, J. Novak, M. Oyama, F. Marken, Electrochem. Commun. 9 (2007) 436. 


\section{Figure Captions}

Figure 1. Schematic illustration of (A) "strong contact" and (B) "weak contact" catalytic processes involving nanoparticles at electrode surfaces. (C-E) Photographs of Kimwipes ${ }^{\circledR}$ samples (C) without treatment, (D) after the seeding treatment (4 nm diameter particles), and (E) after the seed-mediated growth treatment (ca. $20 \mathrm{~nm}$ diameter particles). (F) Schematic and photographs showing the construction of an AuNP-paper-modified GC electrode by fixing AuNP-modified Kimwipes ${ }^{\circledR}$ onto an unpolished GC disk electrode and holding it with a nylon membrane.

Figure 2. (A,B) SEMs for Kimwipes ${ }^{\circledR}$ samples with AuNP deposit visible at high magnification (see B). Cyclic voltammograms (scan rate: $50 \mathrm{mVs}^{-1}$ ) for the oxidation of aqueous $1.0 \mathrm{mM} \mathrm{Fe}(\mathrm{CN})_{6}{ }^{4-}$ measured with $(\mathrm{C})$ an unpolished GC electrode (i) in PBS and (ii) in $\mathrm{KCl}$, (D) a polished GC electrode (i) in PBS and (ii) in KCl, (E) a AuNP-paper-modified GC electrode (by fixing AuNP-modified Kimwipes ${ }^{\circledR}$ onto an unpolished GC disk electrode) (i) in PBS and (ii) in $\mathrm{KCl}$. (F) Voltammograms obtained in PBS for (i) bare GC and (ii) AuNP-Kimwipes ${ }^{\circledR}$ modified GC. (G) The effect of non-modified Kimwipes ${ }^{\circledR}$ on cyclic voltammograms for oxidation of $1.0 \mathrm{mM} \mathrm{Fe}(\mathrm{CN})_{6}{ }^{4-}$ in PBS (i) before contact to Kimwipes ${ }^{\circledR}$, (ii, iii, iv) $2.5 \mathrm{~min}, 5 \mathrm{~min}$, and $10 \mathrm{~min}$ contact to Kimwipes $®$, and (v) after removal of Kimwipes $®$. (H) Nyquist plots for impedance measurements in PBS for (i) a polished GC without paper and (ii) an unpolished GC with AuNPs on Kimwipes®. 

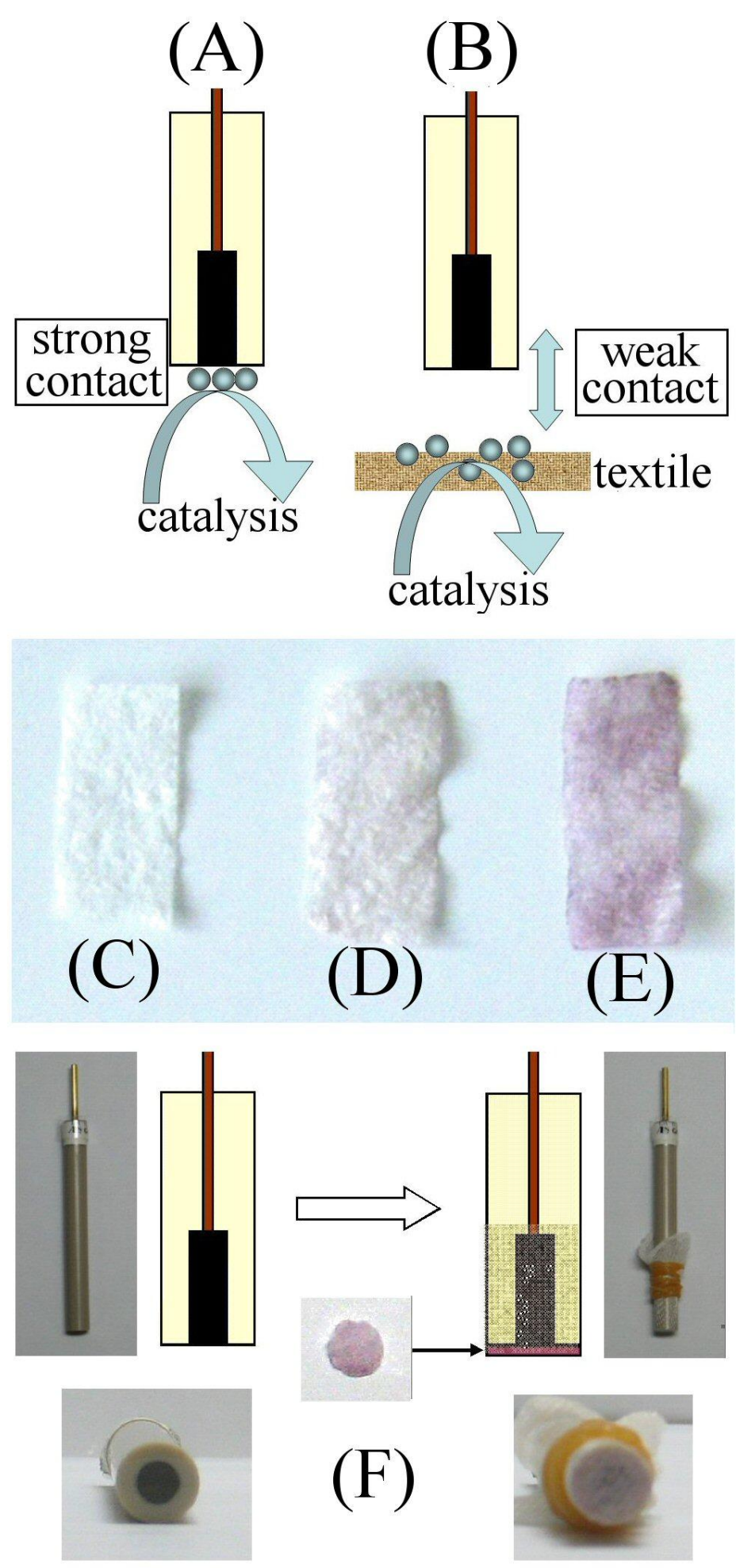

Figure 1. 


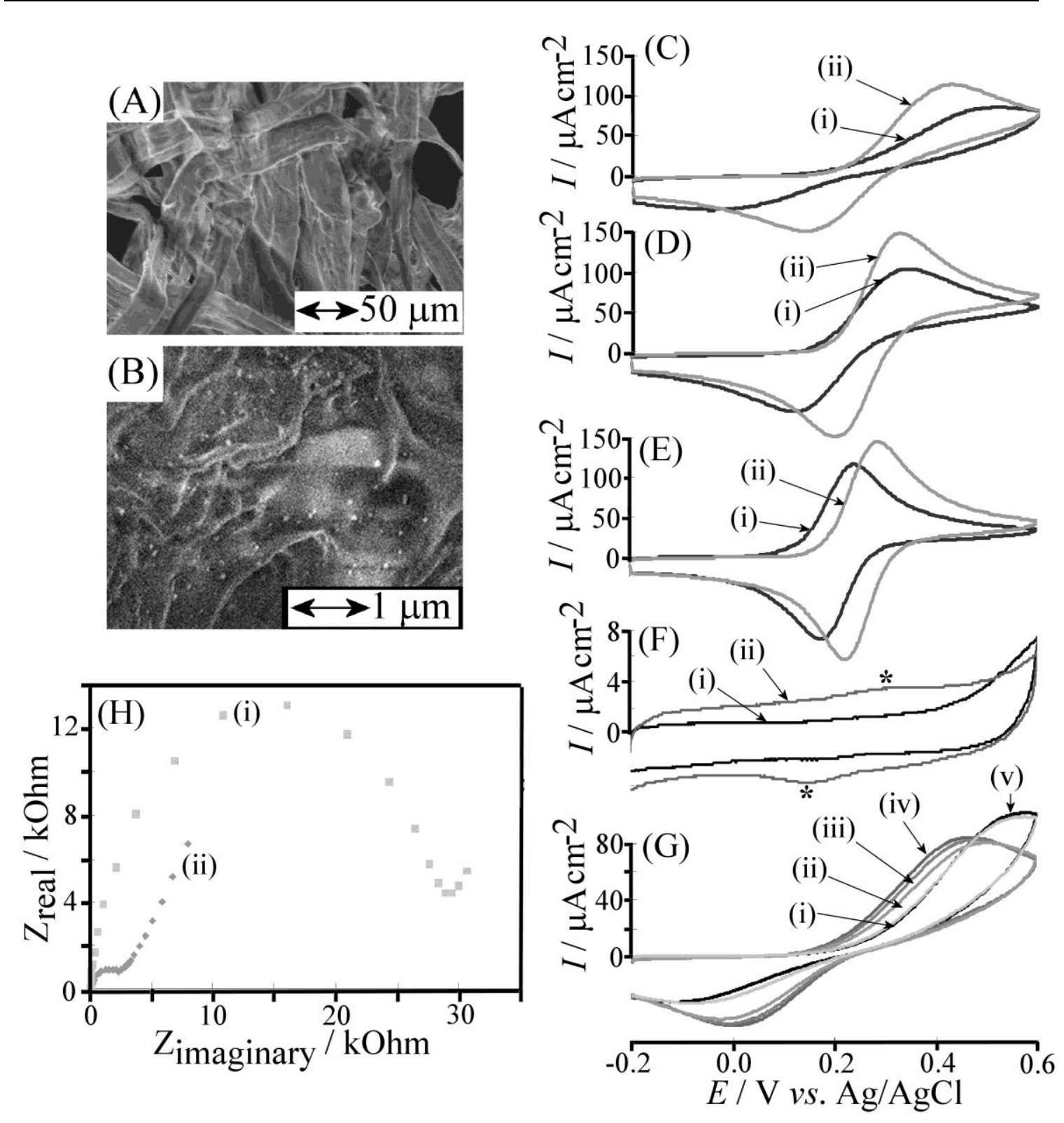

Figure 2. 